\title{
From museum to memory institution: the politics of European culture online
}

Elizabeth Stainforth*

\begin{abstract}
Museums, libraries and archives have long been considered the retainers of some form of collective memory. Within the last twenty years, the term 'memory institution' has been coined to describe these entities, which is symptomatic of the fact that such places are increasingly linked through digital media and online networks. The concept of the memory institution is also part of the vocabulary used to promote broader cultural integration across nations, and appears in discussions of European heritage and in policy documents concerning the digitization of cultural heritage collections. To explore the relationship between cultural heritage, memory and digital technology further, this paper will examine the large-scale digitization project Europeana, under which museums, libraries and archives are re-defined as cultural heritage institutions or memory institutions. My purpose is to trace the conceptual trajectory of memory within this context, and to address how the idea of a European cultural memory structured by technology holds implications for institutions traditionally associated with practices of remembering.
\end{abstract}

Key words: Cultural heritage, collective memory, digitization, network, memory institution, Europe, integration

\section{Introduction}

The concepts of cultural and collective memory are now well-established in academic discourse, and in contemporary cultural heritage debates. Within the organizational context, a number of projects and mission statements use memory as a marker of value and significance; the Library of Congress hosts the American Memory project, UNESCO runs the Memory of the World Programme, Archives UK state of their archival holdings, 'they are our collective memory' (National Archives UK 2015) ${ }^{1}$ and the Australian Government Records invoke 'the memory of our nation' (National Archives of Australia 2015). ${ }^{2}$ Allusions to memory have also been made in discussions of European heritage and in documentation relating to digitization projects. Foremost among these projects is the European Commission (EC) funded Europeana, a database and website that offers access to digitized items from over 2500 of Europe's museums, libraries and archives.

In its policy and strategy documents, the collective term 'memory institution' is frequently used to refer to these sites. For example, in the 2011-2015 Strategic Plan the former Chair of the Europeana Foundation Board, Elisabeth Niggemann (2007-2011), writes,

[Europeana] has facilitated innovative collaboration and knowledge transfer throughout the memory institutions of Europe. The result is a new spirit of collaborative enterprise that is creating a sustainable European information space (Europeana 2011: 4). ${ }^{3}$

Here, the benefits of collaboration and knowledge transfer are highlighted with reference to 'Europe's memory institutions', suggesting that the framework of Europeana facilitates new relationships across organizations and borders. Yet it also hints at a reconceptualization of these organizations in the online environment. Indeed, early definitions of the memory 
institution came from the field of information science, where it was conceived as a metaphor for libraries, archives, museums and clearinghouses, and intended to encourage a coherent view of the information resources they provide (Buckland 2011). A similar drive towards cross-site coherence accounts for its resonance with a large-scale initiative like Europeana, which uses aggregated digital content from discrete national heritage collections. Niggemann's assertion that 'Europeana will become the trusted source of Europe's collective memory' (Europeana 2011: 4) indicates a link between shared experiences of the past and the collective designation of places and resources. This statement also assumes a degree of relevance for contemporary interests - in the case of Europeana, for promoting a culture of European memory. Wood explains how such narratives come to be maintained or perpetuated in Vectors of Memory:

If particular representations of the past have permeated the public domain, it is because they embody an intentionality - social, political, institutional and so onthat promotes or authorizes their entry (1999: 2).

As part of the vocabulary associated with collective memory, the memory institution at once speaks to the objective of cultural integration in Europe, while remaining consistent with the technically distributed elements of the Europeana project. As Dalbello remarks, "pronouncements on the past and future of the European digital heritage space mirror similar teleological and technocratic visions of universal access to European collective memory' (2011: 358). The issues raised by these distinct but related modes of memory, as collective cultural heritage and as networked cultural content, will be the focus of this article through examination of the Europeana case study.

I begin by reviewing the academic field of memory studies, drawing out the relational dynamics implied in the term memory institution. I then consider these dynamics with regard to European memory practices and the EC's goal of trans-national integration, paying specific attention to digital technology and cultural heritage. This survey also provides the background to the Europeana project, which will be addressed in the second section of the article. Europeana's plans and strategy documents are revealing of a tension between museums, libraries and archives and the cultural heritage data generated by the database's aggregated structure. Through exploring this tension, my aim is to critically reflect on the rationale behind Europeana and its development.

\section{Memory Studies and Memory Places}

The concern with memory in popular and academic debates, particularly in the European setting, has been variously described and analyzed as the 'memory boom' (Huyssen 1995; Terdiman 1993), the 'memory industry' (Klein 2000) and the 'memory wave' (Kansteiner 2002), among others. The underlying theme in many of these studies has been the negotiation of Europe's relationship with the past, often through sites, texts and artefacts of remembrance. Such conceptualizations of memory rely on an understanding of cultural forms as practices of memorization, and can be traced to earlier metaphors that presuppose a connection between space and mental categories (Frow 2007: 152). Yates' work on the art of memory investigates these spatial metaphors in the classical mnemonic tradition, which involved the mental arrangement of images and places as a means of situating knowledge so that it would not be forgotten (1966: 3); architectural tropes were especially popular as they were thought to provide the most familiar locations for memory. Notwithstanding the difference between individually constructed mental spaces and physical, collective spaces, the motif of the store-house has implications for both and the storage model of memory continues to occupy a central position in the contemporary field of memory studies.

Within this context, much of the major academic literature draws from Halbwachs' work on the social determination of collective memory, building on his thinking, and developing terms such as 'communicative' and 'cultural' remembrance to account for the transmission of memory through media and cultural forms (Assmann 2010; Olick 2010; Rigney 2005). Halbwachs' insight about the interruption to memory that occurs in the process of writing history (2007: 140) has also been influential in debates that oppose the immediacy of memory to the constructed nature of history. Nora is a notable figure in these debates and he elaborates on 
the distinction between what he calls 'traditional' (living) and 'modern' (material) memory in his collaborative project, Les Lieux de Mémoire, or Places of Memory, written between the years 1984 and 1992. It is his conviction that the memory embodied in the customs and ritual practices of traditional societies has receded, to be replaced by external sites of commemoration that are detached from that experience. This shift in the location of memory is part of the broader issue that Nora distinguishes as the gradual disappearance of primitive or sacred memory in the wake of historical consciousness. He writes, "modern memory is above all archival. It relies entirely on the materiality of the trace, the immediacy of the recording, the visibility of the image' (1989: 13), and proposes 'there are lieux de mémoire, sites of memory, because there are no longer milieux de mémoire, real environments of memory' (1989: 7). However, Nora's study was widely critiqued in the years following its publication (e.g. Confino 1997: 1402; Klein: 2000: 127) on the basis that his argument hinges on the inviolability of 'primitive memory', which Frow describes as a 'nostalgic essentialism that affirms the reality of an origin by proclaiming its loss' (2007: 152). Here, memory figures paradoxically and the modernizing processes that contribute to its disappearance also provide the basis for its reinstitution, albeit in a compensatory manner. In fact, both memory and history may be understood as constructed categories of analysis (Gable and Handler 2011: 36); therefore, situating memory within a longer history of practices and technologies of memorization provides a useful corrective to the essentialist tendencies frequently found in the delineation of pre-modern memorial forms.

The memory institution concept is itself underpinned by assumptions about the materiality of memory and its association with physical places such as museums, libraries and archives. Yet the term's origin in information science at once supports and destabilizes these associations; while the places it designates do have a concrete existence, it is itself constituted in the relations between sites, which can be mapped onto the networked structure of the Internet. The architecture of the Internet lends itself to the integration of digitized material from across cultural heritage collections, and is significant insofar as it facilitates a collective view of past events that is mediated digitally. Van Dijck makes the stakes for memory clear, writing:

The traditional idea of collective memory is generally grounded in the presumption that the individual and the collective are separate entities that are associated through technological mechanisms, such as media, and through social institutions, such as archives. However, the formation of memory is increasingly structured by digital networks, and memory's constituting agency is both technological and human (2010: 2).

The memory institution is no doubt symptomatic of the parallel development and co-existence of analogue and digital technologies (Reading 2012: 144). As such, it allows for a degree of conceptual flexibility and is not immediately incongruous with either of the media-memory models outlined by van Dijck. In practice though, the distributive logic of the digital network is quite different from that of the physical repository. It has also been suggested that the latter is representative of a particularly Euro-centric tradition. As Ernst observes, 'there are different memory cultures. European cultural memory is traditionally archive-centred, with resident material values (libraries, museums, 2500-year-old-architecture), whereas trans-Atlantic media culture is transfer-based' (2004: 52). Before investigating the negotiation of these different memory cultures in the Europeana case study, it is necessary to give some background to the EC's interest in cultural heritage and collective memory and identity.

\section{The EC's Promotion of European Cultural Identity}

Beyond the valorization of memory in the history-memory opposition drawn by Nora, throughout the 1990s memory became a popular means of challenging the perceived authoritarian strain in historical narratives, allowing marginalized and traumatic events to be articulated (e.g. Huyssen 1995: 249; Hutton 1993: 123). However, why and how certain memories have been perpetuated remains important because, as other studies have shown (Gable and Handler 2011; Klein 2000), these are capable of undergoing the same revisions and exclusions as historical discourse. With regard to Europe, research conducted in this area (e.g. Wilson and Smith 1993) has studied such memory practices as part of the process of national identity 
building, made famous by Hobsbawm and Ranger through the concept of invented tradition:

\begin{abstract}
'Invented tradition' is taken to mean a set of practices, normally governed by overtly or tacitly accepted rules and of a ritual or symbolic nature, which seek to inculcate certain values and norms of behaviour by repetition, which automatically implies continuity with the past. In fact, where possible, they normally attempt to establish continuity with a suitable historic past (1992: 1).
\end{abstract}

Hobsbawm goes on to explain how objects and practices inform the invention and reproduction of tradition and implicates the founding of national archives and heritage in what he calls a process of ritualization and formalization (1992: 4). If the rise of national consciousness is demonstrated in attempts to maintain continuity with particular narratives of the past, it is also characterized by a tendency for nations to define themselves against others (van der LeeuwRoord, 2000). In a wider European context, the same move is apparent. As with national identity, there is a symbolic difference by which Europe has historically distinguished itself (Hall, 2003). The active invention of tradition in collective identity building is especially relevant to the study of European institutions such as the EC. In the same way that cultural heritage was used in the formation of nation states, the EC's uptake of collective memory in cultural heritage projects is intimately linked to its wider efforts to forge and popularize a cohesive European identity (Shore 2006: 8).

These efforts have been more pronounced since the expansion of the cultural sector in the 1970s (Tretter 2011) but the focus on unity through shared values and culture began to gain momentum later through the creation of symbols of the kind that could be identified with invented tradition. These included a European flag, the European passport and the creation of a new currency, the Euro, as well as initiatives like the Culture Programme and the European Capitals of Culture (Macdonald 2013: 35). As Shore points out:

The failure of a functionalist approach to political union (as a by-product of economic and technical measures) led to 'a renewed interest in the cultural aspects of integration'. EU policy-makers therefore decided that more 'concrete measures' were needed to enhance the image and identity of the Community through information campaigns and a series of symbolic initiatives (2001: 9).

Such symbolic initiatives have been criticized because their representation of Europe is often based on a highly selective set of cultural influences and universal values (Kansteiner 2002; Passerini 1998). Yet they only constitute part of the strategy by which the EC has sought to further trans-national integration. Another more recent attempt in cultural policy is the motif of unity in diversity (McDonald 1996; Shore 2006), a gesture towards cultural pluralism that also emphasizes the overarching unity of Europe. In theory, it works by promoting European citizenship through cultural diversity in order to loosen national ties. As the EC's 2002 publication, 'A Community of Cultures', stated: 'This idea of European citizenship reflects the fundamental values that people throughout Europe share and on which European integration is based. Its strength lies in Europe's immense cultural heritage' (European Commission 2002a: 3). ${ }^{4}$ Here, the logic of unity in diversity ensures that the former takes precedence over the latter and diversity is only encouraged to the extent that it does not obstruct unity.

Although this contradiction makes it difficult to appreciate the substance of the proposition beyond political rhetoric, anthropological research into the organizational structure of the EC indicates that such contradictions shed light on important aspects of the European project. Abélès discerns a dimension of uncertainty in the working culture of the EC that he relates to the EU's initial principles of engrenage or 'action trap' for cooperation between member states; in agreeing on a specific course of action, member states would find themselves obliged to take another set of actions that pointed in a direction they had not necessarily intended to go (2004: 4). In line with these principles, he suggests that the underlying paradigm of the European political process is less one of unification than of harmonization and rationalization. That is, European political practice begins to influence national politics without spelling out its political goals; he writes: 'Everything is working as if Europe was destined to remain a virtual object' (2004: 6). 
The concept of virtual Europe clarifies the way in which unity in diversity both feeds on and reproduces forms of identification and difference and reflects the indefinite geographical and governmental status of the European entity. If the cultural policy of the EC exemplifies a form of cultural determinism in the sense that political cohesion is the objective of its symbolic initiatives, a similar rationale has been noted in its policy statements about media technologies (Collins 1995: 4; Sarikakis 2007: 76). These determinisms come together in the EC's research programmes concerning the technology framework for museums, libraries and archives.

\title{
Digitizing Culture: The EC's DigiCULT Study
}

The point at which the EC began to show an explicit interest in culture and technology, particularly digitization, can be traced back to its Fifth Framework Programme for Research and Technological Development (1998-2002). Within this framework, the Information Society Technologies (IST) theme received the largest share of funding, and digital heritage and cultural content was one of the five main areas of research and technological development under its 'multimedia content' action (Smith 2002: 42) with a budget of $€ 3,600$ million. Knell (2003: 133) and Parry (2005: 341) have also highlighted the significance of the action plan eEurope 2002: An Information Society for All, endorsed at the Feira European Council in 2000, which identified the need to coordinate digital heritage projects at both a national and European level. To that end, the EC commissioned a 324-page report, entitled Technological Landscapes for Tomorrow's Cultural Economy: Unlocking the Value of Cultural Heritage (or the DigiCULT study), which aimed to provide a 'roadmap' for navigating the political, organizational and technological challenges faced by European museums, libraries and archives in the period 2002-2006. Over six months, 180 international experts from the cultural heritage sector took part in 24 interviews, six expert round tables and two online surveys, helping to shape and define the key issues of the report (Mulrenin 2004: 18). The introduction sets the scene as follows:

\begin{abstract}
Europe's cultural and memory institutions are facing very rapid and dramatic transformations. These transformations are not only due to the use of increasingly sophisticated technologies, which become obsolete more and more rapidly, but also due to a re-examination of the role of modern public institutions in today's society (European Commission 2002b: 9). ${ }^{5}$
\end{abstract}

It is more than ten years since the publication of the study and the period of transformation alluded to here is now in its next phase. Nevertheless, the report was influential regarding the management of digitization activities and digital library development in the Sixth Framework Programme (2002-2006), which, in turn, led to the adoption of a resolution for a European digital library (later launched as Europeana) in the Seventh Framework Programme (2007-2013). It also represents one of the EC's most sustained investigations of technology and cultural heritage to date and therefore provides a detailed snapshot of the organizational landscape at a time that has been described by Dempsey as a foundational moment for digital content management (2006). This factor is important in connection to the characterization of memory in the report and indicates the scale of the EC's thinking and ambition around digital technology during that period. The following section considers how such narratives of memory, both implicit and explicit, manifested themselves in relation to these ambitions.

The DigiCULT study formulated recommendations with both policy makers and cultural heritage sector employees in mind. As such, it covers topics governing future decision-making at an organizational level, a national level and a European policy level. While the report is arranged according to this tripartite structure, perhaps unsurprisingly the discussions frequently feed back into the idea of European cultural heritage. For example, the 'National Policies and Initiatives' section advises governments to encourage cultural diversity within the context of a more socially integrative cultural heritage policy (European Commission 2002b: 36), corresponding with the EC's unity in diversity motif. The section on low-barrier digital access to cultural heritage similarly attempts to negotiate between these two poles, as in its recommendations for the Danish database project, KulturNet:

The primary objective of a European KulturNet should be in communicating 
European culture, taking into consideration cultural diversity as well as similarities between the European countries (European Commission 2002b: 58).

Elsewhere though, questions around technology complicate the general narrative. The report states: 'The conditions for success of the cultural and memory institutions in the Information Society is (sic) the "network logic", a logic that is of course directly related to the necessity of being interoperable' (European Commission 2002b: 80). The recognition that the infrastructure of the Internet has implications for cultural heritage collections is immediately linked to the question of interoperability and systems compatibility. Yet it is also acknowledged that 'interoperability in organisational terms is not foremost dependent on technologies' (Commission 2002b: 80), showing an awareness that 'network logic' will not naturally and inevitably effect structural changes in museums, libraries and archives. Here, the disparity between a hypothetical model and its practical implementation demonstrates the potential difficulty of translating macro-level ideas into a local institutional setting.

In relation to these issues, references to the memory institution, which appear over 100 times in the report, are notable. This is, in part, a preference of one of the authors, former head of the EC's Preservation and Enhancement of Cultural Heritage Unit Bernard Smith, who published several other policy documents emphasizing the term around the same period (e.g. Smith 1996; Smith 2002). However, in much the same way as the network, memory is indicative of a conceptual investment; on the one hand, in how the cultural past is experienced collectively, on the other in a mode of organization or storage. As explained previously, these different understandings feed into and shape one another but there are also moments when they diverge in the report, especially regarding technical matters such as digitization. The view that the digital medium is 'profoundly democratic' (European Commission 2002b: 36) informs the focus on access to cultural heritage and its vision of digitization services that allow people 'to contribute their own story to the cultural memory' (European Commission 2002b: 55). By the same token, assumptions about the existing record of cultural memory are apparent in statements endorsing the expertise of cultural heritage institutions in developing criteria for digitization projects (European Commission 2002b: 84). The ambiguity of memory has been commented on by scholars investigating heritage and memory institutions in other EU projects too (Manžuch 2009; Dalbello 2008) and is in some cases attributed to the types of resources they manage; what could be called informational memory dominates discussions of archives and libraries, while cultural memory is more closely aligned with museums (Manžuch 2009; Knell 2003). In the DigiCULT study, it could be argued that the notion of the memory institution constitutes a means of joining the former with the latter. For, while there is no question that the report's use of the term is a metaphor for museums, libraries and archives, it also to some extent anticipates the European digital heritage space that would ultimately find form in Europeana.

\section{Development of Europeana: Europe's Digital Library}

The memory institution concept is one attempt to negotiate what were earlier described as resident and transfer-based cultures of memory and the emergence of digital libraries represents a comparable process. It has been observed that such entities can be made up of numerous technologies, including Internet Protocol, digitization, electronic storage, servers, metadata and search and retrieval systems (Béquet 2009). ${ }^{6}$ This is relevant because Europeana itself started out as a proposal for a European digital library. Therefore, further consideration of the technical elements and decision-making are required to give an insight into the rationale behind the project.

The original impetus for the initiative was to safeguard Europe's cultural heritage after the announcement of the Google Books Project in 2005 (Purday 2009), beginning with the mass digitization of five of the world's most extensive library collections (University of Michigan, Harvard, Stanford, Oxford and the New York Public Library). There were worries that Google would end up transferring a large volume of cultural resources into the private sector, and so the proposal was made for an equivalent European programme that was open access, with non-exclusive rights (Purday 2009). A notable figure in the Google Books debate was JeanNoel Jeanneney, Director of the National Library of France (2002-2007), who first called for a European campaign to counter the commercial focus of Google's project in January 2005 (Béquet 
2009). This call was taken up by the then President of France, Jacques Chirac (1995-2007), in April of the same year. In a letter paying tribute to the richness and diversity of European heritage collections, Chirac, with support from the leaders of Germany, Hungary, Italy, Poland and Spain, proposed the establishment of a digital European library (European Commission 2005). ${ }^{7}$ The President of the EC responded positively to the letter and subsequent backing from the i2010: Digital Libraries Initiative, the Ministers of Culture of the Member States and the European Council led to the successful vote, which gave the go-ahead for the commencement of the Europeana project in 2007. At the unveiling of the i2010 Strategy, former Information Society and Media Commissioner Vivian Reding (2004-2009) spoke of memory directly, stressing, 'without a collective memory, we are nothing, and can achieve nothing. It defines our identity and we use it continuously for education, work and leisure' (Europa 2005). ${ }^{8}$ The comment, made in the context of the Internet's capacity for storing and sharing information, is in-keeping with the media-memory metaphors in the DigiCULT report and suggestive of the alignment of digital technologies with the storage model of memory at that time.

The fact that Europeana was understood as a digital library is also significant in this regard and informed the portal model on which it was initially based. The prototype database was launched in November 2008 as a proof of concept, providing access to content from across European cultural heritage collections via the website www.europeana.eu. In the early stages of the project it was decided that Europeana would not store digital objects on a central server, partly because of cost implications and partly because some national libraries had already carried out large-scale digitization activities (Erway 2009). Instead, it would function as an aggregator of metadata about existing digital objects and point to the institutional sites where they were held. Therefore, a great deal of technical effort went towards the development of the European Data Model (EDM) for metadata, with the aim of creating interoperability between discrete digital collections. Europeana was envisaged as the cross-cultural, multilingual venue for accessing these collections and the project relied on the collaboration of museums, libraries and archives from the outset. As such, it has progressed with multiple user bases in mind, concentrating on cultural institutions and individuals, then later branching out to creative enterprises and professionals (Europeana 2014a: 11). ${ }^{9}$ The distributed network database model distinguishes Europeana from projects like Google Books, which stores digital files in a single database, and demonstrates the different functions implicit in the concept of the digital library. Likewise, the naming of Europeana is indicative of its ambition to go beyond associations with particular institutions. This umbrella term currently encompasses a number of organizations, consisting of the Europeana Network and Tech community, more than 2500 content-contributors, 25 EU-funded projects, a board of content holders, a Member State Expert Group and an Executive Office of 50 full-time employees (Europeana 2014b: 8). ${ }^{10}$

Since its launch, Europeana has amassed a large volume of digital content, consistent with its strategic aim of reaching 30 million items in 2015 (Europeana 2011: 13). The scale of the target matches the project's scope: to be a comprehensive and representative source for Europe's cultural heritage. However, faced with such vast collections, a selective approach has been required to make the content serviceable. For example, in 2013 its website was relaunched with a stronger focus on curated content and a bigger image slideshow (Europeana 2011: 9). The new site is heavily oriented towards images in its design and presentation and the reference to curated content applies primarily to the introduction of an 'Exhibitions' page. Designed as a showcase for Europeana's collections, these exhibitions are comprised of images grouped under different headings with additional descriptive information. Unified cultural and historical themes are highlighted, ranging from monuments, artistic movements and historical events, to topics that make their trans-national affiliations plain, e.g. 'Being European' and 'The Euro'. All exhibitions are available in English, and the majority are available in French and German. This hierarchy loosely reflects the languages spoken in the EU at an organizational level but is less reflective of the European identity that Europeana claims to embody.

Furthermore, countries such as France and Germany have significantly larger contributions than other EU member states, meaning that their own national collections have better coverage. While these inconsistencies are to some extent unavoidable (in the case of France, there was sustained government support and funding through the culture.fr initiative), it 
makes it more difficult to justify the claim that Europeana is a comprehensive cultural resource.

Such issues are implicitly linked with the memory institutions from which the majority of digital material is sourced and the role of information management processes in constructing representations of cultural heritage. As noted, because it is an aggregator, Europeana holds the metadata about digital objects, but access to the digital objects themselves are from the providers' sites, which means that they retain the navigation and context relevant to the collections. Consequently, the designs of online exhibitions are influenced by the pre-existing collections structures of individual (national) organizations. Dalbello observes a similar precedent for the arrangement of physical collections to be reproduced in digital projects. Writing of the cultural record that heritage institutions are concerned with maintaining, she argues that 'studying how digital libraries are involved in the production of knowledge is crucial to our understanding of how memory institutions are currently shaping this record in the digital environment' (Dalbello 2004: 267). Europeana has sought to replicate and maintain such institutional integrity as part of its distinctiveness. Defining itself as the trusted source of Europe's cultural heritage online, the website guarantees that 'Europeana always connects you to the original source of the material so you can be sure of its authenticity' (EuropeanaLocal 2016). ${ }^{11}$

The need for Europeana to be a trusted source of cultural heritage is perhaps related to its user base at an individual level. The promotion of Europeana's content to enhance learning and teaching (Europeana 2011: 16) places students and teachers at the heart of its priority to demonstrate public value and links back to its funding, which is partially reliant on Member States' ministries of culture and education. However, cultural tourists are also included in its audience remit, and coordination with the European Capitals of Culture programme and the Council of Europe's Directorate of Culture and Cultural and Natural Heritage is actively encouraged (Europeana 2011: 17). A closer examination of Europeana's strategy is revealing of its attempt to balance the demands of openness and accessibility with reputable content, and the change in its strategic priorities in line with shifts in web culture.

\section{Europeana's Strategy: From Portal to Platform}

In its early years (2008-2011), Europeana was a predominantly technical project, supported by experts in digital information systems, who concentrated on building its database and website. Later (2014-present), because of its range of interests and partners, it was increasingly portrayed as a network of people and projects, using the platform metaphor as a way of expressing its interaction between distinct but interdependent groups (Europeana 2014a: 11). Technical language has influenced the conceptualization and organization of Europeana throughout its lifespan. Bowker suggests that this convergence is fundamental to information infrastructures, writing, 'our way of organizing information inside a machine is typically a mediation on and development of the way we organize the world' (2005: 31). The point again calls to mind the EC's wider ambition of European cohesion and Abélès' notion of virtual Europe, understood as a process of harmonization and rationalization. In the case of Europeana, it is possible to discern a similar process, channelled through decentralized technical and cultural operations, with the aim of fostering trans-national integration.

The relational structure of these operations gestures back to the memory institution, but within a scheme of informational memory, rather than the cultural memory associated with 'resident values' (Ernst 2004: 52). Nevertheless, the cultural status of such institutions is central to the mission of Europeana, as outlined in its first Strategic Plan (2011-2015). Memory institutions are highlighted in the foreword to this document (Europeana 2011: 4), which is related to its objective of becoming 'established as the trusted and comprehensive resource for authoritative cultural heritage content from across Europe' (Europeana 2011: 16). Here, it appears to be the case that the project is rooted to an idea of museums, libraries and archives that is synonymous with fixed sites of authority and authenticity (Smith 2006: 11). Equally, the statement of 'Europeaness' inflected in its view of cultural heritage inevitably constrains the drive towards 'pan-European, cross-domain content (that) creates new juxtapositions and opens up new interpretations' (Europeana 2011: 18). The 2011-2015 Plan often articulates these types of contradictions; while recognizing the need to move away from a dominant discourse (e.g. Europeana 2011: 18), the significance of the flagship Europeana brand is 
nevertheless repeatedly brought to the fore (e.g. Europeana 2011: 16). Likewise, the view of European culture as an end in itself vies with the obligation to provide a means of engaging with culture, as in the following extract:

We are working with partners that specialise in User Generated Content [...] on models that allow Europeana to bring in user content without compromising our authoritative positioning and with appropriate levels of mediation (Europeana 2011: 19).

Hence, user-generated content is encouraged but not so far as to compromise the 'authoritative positioning' of Europeana's collections. Further evidence of this tendency can be found in its strategic priority to optimize social media activities, to drive a larger percentage of user traffic to the Europeana website (Europeana 2011: 16). The value of social media is measured by its potential to generate publicity for the project, reflecting the 'culture portal' side of the model. It is interesting to note the disjuncture between the distributed network structure of the database itself and the instrumentalization of social networks for the purposes of creating a centre of gravity around the website. In fact, the participation and engagement facilitated by these platforms and created in the relations between sites, is at least as relevant for the experience of collective memory in a Europe that is increasingly characterized by rapid, technologically driven cultural changes. The attempt to hold two models of memory and two modes of organizing information concurrently results in a tension between access to culture (as administered by memory institutions) and participation in culture (as part of a broader set of activities online).

More recently, Europeana has shown a growing awareness of these issues, bringing about a reconsideration of its role as a single access point to European culture. In its latest strategy document, Europeana 2020, the section headed 'From Portal to Platform' acknowledges the need 'to start behaving like a platform - a place not only to visit but also to build on, play in and create with' (Europeana 2014a: 10). The platform model represents a huge leap from the DigiCULT report's commentary on 'network logic' and its downplaying of technological interoperability. In 2002, the organizational barriers to technology were perceived to be difficult to overcome. What the subsequent development of digital libraries, including Europeana, began to illustrate was that interoperable collections data could build bridges between museums, libraries and archives (Marton 2011: 213). In the 2020 Strategic Plan, the negotiation between the authoritative positioning of memory institutions and access to cultural information has shifted towards the latter in line with the wider uptake of Internet technologies. Therefore, while references to memory institutions continue, it is more often within a narrative of accessibility and visibility, through which Europeana undertakes to disseminate their collections to wider audiences: 'memory institutions get the visibility, cost reductions and return they deserve from tapping into a shared infrastructure' (Europeana 2014a: 18).

Instead of promoting the portal as a destination website, this approach involves making the content easier to re-use or export, as well as feeding into other sites that users habitually use, like Wikipedia and Flickr (Europeana 2014a: 12). The emphasis on re-use and participation is mirrored at an organizational level in the re-branding of Europeana as a network, a structure that is an explicit assertion of its collaborative working practices. The Network consists of individuals who have professional connections with the core aims of Europeana's digitization activity, and task forces, comprised of Network members, to work on areas including user-generated content, metadata quality and content re-use (Europeana 2014a: 25). The thinking has clearly moved on from the logic of gathering together that was a feature of the earlier strategy.

Europeana 1914-1918, a project for the First World War Centenary, offers a practical example of this thinking. Using the Europeana database, online content was aggregated from national collections, in conjunction with several European roadshows, where people brought their manuscripts and memorabilia from the war to be digitized. There was also an online collections form on the website, where personal stories and images could be uploaded. The idea was based on the Great War Archive's Community Collection Model in Oxford, which set up a public Flickr group after its digitization funding ended, to sustain the life of the project without professional moderation (RunCoCo 2015). ${ }^{12}$ The intention was that, through a mixture of stories from the public, national collections and film archives, the experiences of the First 
World War could be communicated from diverse perspectives, across Europe and the world. Such initiatives go some way towards addressing earlier criticisms about the uneven national collections coverage on Europeana; by inviting individual and collective world-wide contributions, the project speaks to the broader context and impact of WWI. In addition, all the material is available for re-use, which allows for adaption of the content.

However, the question of funding that was relevant in the Oxford case is also relevant to Europeana, and part of the reason for its shift towards a network model in organizational terms is connected to its sustainability plan for 2015 onwards. Under the 2011-2015 Strategic Plan, Europeana received funding of around $€ 30$ million a year from the ICT-PSP Competitiveness and Innovation programme, but for the period 2015-2020 its funding was transferred to the Connecting Europe Facility (CEF), a programme that had its budget cut from $€ 9$ billion to under $€ 1$ billion (Europeana 2014c: 2 ; 4). ${ }^{13}$ Under CEF, initiatives were required to move towards self-sustainability, which for Europeana meant becoming 'a more entrepreneurial and service-centred operation [...] embedded in and supported by the Europeana Network' (Europeana 2014c: 1). The financial imperatives, coupled with developments in technology, inform this move. It is perhaps unsurprising, then, that the new Strategic Plan often alludes to technical infrastructure when highlighting the benefits of the Network, as in recommendations for open source publishing, knowledge exchange services and the hosting of co-creation spaces (Europeana 2014a: 4).

Of course, European identity is still important to Europeana's vision, and to some extent it is the rhetoric of connectedness that comes to the fore in the 2020 Strategy; the affirmation of trans-nationalism is apparent in the statement that 'a culturally connected Europe is a better Europe' (Europeana 2014a: 19). Less discussed is how connected services might enable more democratic memory making practices; the notion that museums, libraries and archives are repositories for collective memory remains largely unchallenged, raising questions about how far constructing the user as an active participant leads to greater participation (Cox and McLean 2012; Dean 2009). The capacity of networks and platforms, on their own, to enable the social interaction implied by participation is likewise uncertain. Comments made by Nick Poole are interesting in this regard. Poole was the Chair of the Europeana Network (20102014) and the Chief Executive Officer of the Collections Trust up until 2015, the organization that managed the UK aggregator for Europeana cultural heritage data. His ambivalence about aspects of the project is perceptible in his reflections on memory:

I think people want experiences that give them access to a sense of collective cultural
memory. I think that they also want experiences that enable them to contribute to
that collective cultural memory as an ongoing process. I think we are only at the
earliest stages of understanding how to use technologies such as the Internet
and mobile platforms to support that experience. I hope that in future the physical
and digital experience of collective memory will be seamlessly integrated, so that
they augment each other, but for the time being, putting collections online is a
very blunt way of providing access to one part of that experience. (Poole 2014). ${ }^{14}$

In this statement, there is an acknowledgement of the transitional phase in Europeana's development. As has been demonstrated, the memory metaphor is mobilized by the EC at a trans-national, national and user level, with the elusive aim of achieving unity in diversity. Poole, though, shows an implicit recognition that the online platforms used to facilitate collaboration, access and re-use do not necessarily lead to experiences of connectedness or engagement. Such an admission hints at the problems of conflating the logic of networked memory with the process of collective remembrance but also resonates with van Dijck's earlier observation that the constituting agency of memory is increasingly technical and social. The potential influence and impact of such a relationship is obvious, even if there are not yet answers to many of the questions about the ethics and politics of digital technologies as mediators of cultural engagement. As van Dijck suggests, understanding how contemporary experiences and memories are constructed requires more nuanced research into the interplay between these technologies, the connective work of human contributors and institutional selection mechanisms (2010: 11). 


\section{Conclusion}

In her anthropological study Memorylands: Heritage and Identity in Europe Today, Macdonald calls attention to the importance of research into memory practices in specific locales, including European institutions, to address the continual re-imagining of histories, nations, and cultures (2013: 34). She cautions:

So much policy and practice hinge on assumptions about matters such as that 'memory' will be materialised in certain ways, that 'communities' will typically have a discrete and distinctive body of heritage that they will want to maintain and present, that certain events will be recalled, perhaps even in similar ways, across Europe and that 'shared' heritage will necessarily bind people together (2013: 226).

My argument here has attempted to interrogate these assumptions from the perspective of the memory institution and its use within a policy framework relating to digitization. Rather than focusing on the narratives and representations of the heritage space itself, I examined a wider discursive and material space, across which museums, libraries and archives come into contact with one another. Narratives and representations are still important, as they express themselves in this relational structure, particularly with regard to memory. The EC's drive to establish a broader memorial culture across nations offers one such articulation, revealing the interests of a geo-political entity aspiring toward a supranational, trans-national identity. Digital memory is another, finding form in both virtual systems of networked communications and as a means of accumulating, storing and retrieving information. These modes of memory have quite different proclivities: where one is defined by unity and discrete cultural entities, the other has a distributive, cumulative future-oriented drive, which throws up difficulties when they are combined, both in theory and practice. Analysis of the EC's policy exposed a range of related issues, showing how networked cultural resources and memory institutions operate within a broader agenda of trans-national integration. The Europeana case study has provided an opening for exploring these issues and thinking through the implications for practices associated with media-memory cultures in Europe.

Received 11 August 2015 Finally Approved 10 June 2016

\section{Notes}

1 National Archives UK (2015) 'Leading Archives', http://www.nationalarchives.gov.uk/ archives-sector/leading-archives.htm

2 National Archives of Australia (2015) 'About Us', http://www.naa.gov.au/about-us/

3 Europeana (2011) 'Strategic Plan 2011-2015', Brussels, http://www.pro. europeana.eu/c/document library/get_file?uuid=c4f19464-7504-44db-ac1e3ddb78c922d7\&groupld=10602

4 European Commission (2002a) 'A Community of Cultures: The European Union and the Arts', Directorate-General for Press and Communication, Brussels, www.programculture. cz/res/data/002/000251.pdf

5 European Commission (2002b) 'Technological Landscapes for Tomorrow's Cultural economy: Unlocking the Value of Cultural Heritage', DigiCULT Report, Luxembourg: Official Publications of European Communities, http://www.digicult.info/pages/report.php

6 Béquet, G. (2009) 'Digital Library as a Controversy: Gallica vs Google'. 9th Conference Libraries in the Digital Age, Dubrovnik, Croatia, https://halshs.archives-ouvertes.fr/hal$\underline{00718385 / \text { document }}$ 
7 European Commission (2005) Scanned copy of letter by Jacques Chirac and Gerhard Schröder to José Manuel Barroso, 28 April 2005, http://ec.europa.eu/information_society/ activities/digital libraries/doc/letter 1/index en.htm

8 Europa (2005) 'Commission Unveils Plans for European Digital Libraries', http://europa. eu/rapid/press-release IP-05-1202 en.htm?locale=en

9 Europeana (2014a) 'Europeana Strategy 2015-2020', Brussels, http://pro.europeana.eu/ files/Europeana Professional/Publications/Europeana\%20Strategy\%202020.pdf

10 Europeana (2014b) ‘Business Plan', http://pro.europeana.eu/files/Europeana Professional/ Publications/Europeana\%20Business\%20Plan\%202014.pdf

11 EuropeanaLocal (2016) 'Europeana', http://www.europeanalocal.eu/eng/Europeana

12 RunCoCo website (2015) 'Projects and Case Studies', http://projects.oucs.ox.ac.uk/runcoco/ casestudies/index.html

13 Europeana (2014c) ‘Europeana Strategy 2020, Network \& Sustainability (draft)', http://pro. europeana.eu/files/Europeana_Professional/Publications/Europeana $\% 20$ Strategy $\% 20$ Network\%20Sustainability.pdf

14 Poole, N. (2014) Unpublished interview with the author.

\section{References}

Abélès, M. (2004) 'Identity and Borders: An Anthropological Approach to EU Institutions', Twenty-First Century Papers: On-Line Working Papers from the The Center for 21st Century Studies, Number 4, 1-26, https://www4.uwm.edu/c21/pdfs/workingpapers/ abeles.pdf

Assmann, Jan. (2010) 'Communicative and Cultural Memory' in A. Erll, A. Nünning, S. B. Young (eds.) A Companion to Cultural Memory Studies, 109-118, New York: De Gruyter.

Bowker, G. C. (2005) Memory Practices in the Sciences, London: MIT Press.

Buckland, Michael (2012) 'What Kind of Science Can Information Science Be?', Journal of the American Society for Information Science and Technology, 63 (1) 1-7.

Collins, R. (1995) 'Reflections Across the Atlantic: Contrasts and Complementarities in Broadcasting Policy in Canada and the European Community in the 1990s', Canadian Journal of Communication, 20 (4) 483-504.

Confino, A. (1997) 'Collective Memory and Cultural History: Problems of Method', The American Historical Review, 102 (5) 1386-1403.

Cox, G. and McLean A. (2012) Speaking Code: Coding as Aesthetic and Political Expression, Cambridge, MA: MIT Press.

Dalbello, M. (2004) 'Institutional Shaping of Cultural Memory: Digital Library as Environment for Textual Transmission', Library Quarterly, 74 (3) 265-298.

Dalbello, M. (2008) 'Cultural Dimensions of Digital Library Development, Part I: Theory and Methodological Framework for a Comparative Study of the Cultures of Innovation in Five European National Libraries', Library Quarterly, 78 (4) 355-395. 
Dean, J (2009) Democracy and Other Neoliberal Fantasies: Communicative Capitalism and Left Politics, Durham, NC: Duke University Press.

Dempsey, L. (2006) 'The (Digital) Library Environment: Ten Years After', Ariadne, 46, http:// www.ariadne.ac.uk/issue46/dempseyl

Ernst, W. (2004) 'The Archive as Metaphor: From Archival Space to Archival Time', Open, 7, 46-53.

Erway, R. (2009) 'A View on Europeana from the US Perspective', Liber Quarterly, 19 (2) 103-121.

Frow, J. (2007) 'Toute la Mémoire du Monde: Repetition and Forgetting' in M. Rossington and A. Whitehead (eds.) Theories of Memory: A Reader, 150-156, Edinburgh: Edinburgh University Press.

Gable E. and Handler R. (2011) 'Forget Culture, Remember Memory?' in M. Williamson Huber (ed.) Museums and Memory, 23-44, Knoxville, Tenn: Newfound Press, University of Tennessee Libraries.

Halbwachs, Maurice, 'The Collective Memory' in M. Rossington and A. Whitehead (eds.) Theories of Memory: A Reader, 139-143, Edinburgh: Edinburgh University Press.

Hall, S. (2003) '“In but not of Europe': Europe and its Myths' in L. Passerini (ed.) Figures d'Europe: Images and Myths of Europe, 35-46, Brussels: Peter Lang.

Hobsbawm, E. and Ranger, T. (1992) The Invention of Tradition, Cambridge: Cambridge University Press.

Hutton, P. H. (1993) History as an Art of Memory, Hanover: University Press of New England.

Huyssen, A. (1995) Twilight Memories: Marking Time in a Culture of Amnesia, New York: Routledge.

Kansteiner, W. (2002) 'Meaning in Memory: A Methodological Critique of Collective Memory Studies', History and Theory, 41 (2) 179-197.

Klein, K. (2000), 'On the Emergence of Memory in Historical Discourse', Representations, 69, Special Issue: Grounds for Remembering, 127-150.

Knell, S. J. (2003) 'The Shape of Things to Come: Museums in the Technological Landscape', Museum and Society, 1 (3) 132-146.

Macdonald, S. (2013) Memorylands: Heritage and Identity in Europe Today, London: Routledge.

Marton A. (2011) Forgotten as Data - Remembered through Information. Social Memory Institutions in the Digital Age: The Case of the Europeana Initiative, PhD thesis, The London School of Economics and Political Science.

McDonald, M. (1996) '“Unity in Diversity”. Some Tensions in the Construction of Europe', Social Anthropology, 4, 47-60.

Manžuch, Z. (2009) 'Archives, Libraries and Museums as Communicators of Memory in the European Union Projects', Information Research, 14 (2), http://www.informationr.net/ ir/14-2/paper400.htm|\#grah-2004 
Mulrenin, M. (2004) 'DigiCULT: Unlocking the Value of Europe's Cultural Heritage Sector' in J. Hemsley, V. Cappellini \& G. Stanke (eds.) Digital Applications for Cultural and Heritage Institutions: Selected Papers from the EVA Conferences, 17-25, Aldershot: Ashgate Publishing.

Nora, P. (1989) 'Between Memory and History: Les Lieux de Mémoire', Representations, 26, Special Issue: Memory and Counter-Memory, 7-24.

Olick, J. K. (2010) 'From Collective Memory to the Sociology of Mnemonic Practices and Products' in A. Erll, A. Nünning, S. B. Young (eds.) A Companion to Cultural Memory Studies, 151-162, New York: De Gruyter.

Parry, R. (2005) 'Digital Heritage and the Rise of Theory in Museum Computing', Museum Management and Curatorship, 20 (4) 333-348.

Passerini, L. (ed.) (1998) The Question of European Identity: A Cultural Historical Approach, Florence: European Historical Institute.

Purday, J. (2009) 'Think Culture: Europeana.eu from Concept to Construction', Bibliothek: Forschung und Praxis, 33 (2) 170-180.

Reading, A. (2012) 'Globital Time: Time in the Digital Globalised Age' in E. Keightley (ed.) Time, Media and Modernity, 143-161, New York: Palgrave Macmillan, 2012.

Rigney, A. (2005) 'Plenitude, Scarcity and the Circulation of Cultural Memory', Journal of European Studies, 35 (1) 11-28.

Sarikakis, K (2007) 'Mediating Social Cohesion: Media and Cultural Policy in the European Union and Canada' European Studies, 24, 65-90.

Shore, C. (2001) 'European Union and the Politics of Culture', Paper no: 43. The Bruges Group, London.

Shore, C. (2006) 'In uno plures' (?) EU Cultural Policy and the Governance of Europe', Cultural Analysis, 5, 7-26.

Smith, B. (1996) 'The European Union and Serials Publishing: Impact and Influence', Serials, 9 (3) 251-268.

Smith, B. (2002) 'Digital Heritage and Cultural Content in Europe', Museum International, Heritage Issues in the Information Society [2], 54 (4) 41-51.

Smith, L. (2006) Uses of Heritage, London: Routledge.

Terdiman, R. (1993) Present Past: Modernity and the Memory Crisis, New York: Cornell University Press.

Tretter, E. (2011) 'The 'Value' of Europe: The Political Economy of Culture in the European Community', Geopolitics, 16 (4) 926-948.

van der Leeuw-Roord, J. (2000) 'Working with History - Developing European Consciousness' in S. Macdonald (ed.) Approaches to European Historical

Consciousness - Reflections and Provocations, 114-124, Hamburg: Körber-Stiftung.

van Dijck, J. (2010) 'Flickr and the Culture of Connectivity: Sharing Views, Experiences, Memories', Memory Studies, 10, 1-15.

Wood, N. (1999) Vectors of Memory: Legacies of Trauma in Postwar Europe, Oxford: Berg. 
Wilson T. M. and Smith E. M. (1993) Cultural Change and the New Europe: Perspectives on the European Community, Westview: Boulder.

Yates, F. (1966) The Art of Memory, London: Routledge and Kegan Paul.

\section{Acknowledgements}

I would like to thank Professor Eric Gable for his feedback and suggestions regarding earlier versions of this article.

*Elizabeth Stainforth is a PhD candidate in the School of Fine Art, History of Art and Cultural Studies, University of Leeds. Her research investigates the contemporary significance of memory for cultural heritage in the wake of digital technologies. She has worked as a researcher and tutor and is one of the editors of parallax journal. She also works for Leeds University Library, where she has been involved in projects with the Digital Content and Repositories Team, Special Collections and the Stanley \& Audrey Burton Gallery.

\section{Address}

Stanley \& Audrey Burton Gallery

University of Leeds

Woodhouse Lane

Leeds LS2 9JT

United Kingdom

Email: e.m.stainforth@leeds.ac.uk 